\title{
A comparison of a first and final year UG enterprise unit: lessons from experiential learning and interdisciplinarity
}

\section{Sanchez-Romaguera, Veronica and Phillips, Robert A.}

Manchester Enterprise Centre, Alliance Manchester Business School, University of Manchester, UK

\begin{abstract}
Drawing from several years of experience, this work describes lessons learnt in designing, delivering and assessing two interdisciplinary enterprise units offered to undergraduate students from any discipline studying at the University of Manchester in the United Kingdom(UK). Both units are electives (optional). One unit is delivered to first year undergraduate students whereas the other unit is delivered to final year undergraduate students. Experiential learning and interdisciplinary cohorts are core aspects of both units. Students work on 'real-world' projects to develop a credible creative solution to a tight dead-line.

In this paper, findings are drawn from data collected from staff and teaching assistants observations, students' reflective diaries and students' feedback. Findings showed that in general, students at both levels, year 1 and year 3/4, regarded the experience as challenging at first due to the 'unusual' learning environment when compared to the education that most students have experienced prior to the units here discussed. However, most students regarded highly the interdisciplinary experiential learning experience. This paper contributes to the growth of knowledge and aids understanding of how experiential learning and interdisciplinarity have been effectively combined and introduced in the university curriculum. Although this work focusses on enterprise education, the experience-based guidance described is also applicable to a much wider range of situations and academic areas of study.
\end{abstract}

Keywords: Enterprise and Entrepreneurship Education; Employability; Experiential learning; Interdisciplinary education. 


\section{Introduction}

\subsection{Enterprise and Entrepreneurship Education (EEE), Employability and Higher}

\section{Education}

Across the globe, governments and policy makers have recognised that an entrepreneurial society offers a sound basis for sustainable environmental stewardship, economic renewal and social inclusion, for the creation of new jobs and advances in human welfare (Volkman et al., 2009). To some extent, in response to such agendas, Higher Education Institutions (HEIs) are increasingly taking a key role developing new enterprise and entrepreneurship education strategies and practices approaches to encourage entrepreneurial mindsets and enterprising behaviour among university students through their enterprise and entrepreneurship teaching initiatives (Jones et al., 2015).

A multitude of definitions of EEE exist can be found in the literature. Here we followed definitions from QAA (2018) guidelines for enterprise educators, which have their foundations in Gibbs' (2005) framework. Enterprise is defined as the generation and application of ideas, which are set within practical situations during a project or undertaking. Skills, attributes and behaviours associated to enterprising individuals combine creativity, originality, idea generation, design thinking, adaptability and reflexivity with problem identification, problem solving, innovation, communication, initiative and practical action. Enterprise education focuses upon the development of the enterprising person and the enterprising mindset through a demonstration of enterprising skills, behaviours and attitudes across a diversity of contexts. Entrepreneurship is defined as the application of enterprise behaviours, attributes and competencies into the creation of cultural, social and/or economic value. Intrapreneurship is the application of enterprise behaviours, attributes and skills within an existing micro or small business, corporate or public-sector organisation. Entrepreneurship education is very much focused on the processes and practicalities of how to start a business and is often taught via the development of a business plan.

It has been widely recognised that learning 'about', 'for', and 'through' Enterprise and Entrepreneurship whilst at university can have several benefits, including enhancing students employability, according to Knight and Yorke (2003), within a higher education contextis defined as 'a set of achievements - skills, understandings and personal attributes that make individuals more likely to gain employment and be successful in their chosen occupations, which benefits themselves, the workforce, the community and the economy.' EEE can help develop a 'can-do' attitude, confidence, a creative questioning approach, and a willingness to take risks, enabling individuals to manage workplace uncertainty and flexible working patterns and careers. Enterprising competencies, such as teamwork and the ability to demonstrate initiative and original thought, alongside self-discipline in starting 
tasks and completing them to deadlines, are essential attributes that have been identified by employers as priorities. Further to that, it gives students alternative perspectives on their career options and ultimately, the confidence to set up their own business or social enterprise. Enterprise competencies will be useful to those in employment, or those who become self-employed and work on a freelance or consultancy basis. Therefore, EEE can help young people develop a range of skills and attitudes that are useful for modern employment as well as widening their social perspectives as well as place self-employment and entrepreneurship on a par with 'traditional' forms of employment (Jones and Iredale, 2014; QAA, 2018).

With the growing demand for EEE, in a quest for the identification of the best pedagogical approaches, several scholars have examined the evolution and effectiveness of pedagogies in EEE. In recent work Jones (2015) concludes that among scholars, there seems to be a consensus that the best results in enterprise and entrepreneurship education are achieved when students are exposed to experiential learning approaches rooted in Kolb's experiential learning theory (Kolb, 1984). These approaches known as Problem Based Learning (PBL), Enquire Based Learning (EBL), amongst others, have been shown to be an effective learning pedagogy by integrating problem-solving, creativity, and reflection. A comprehensive literature review including scholarly publications examining the evolution and effectiveness of experiential learning pedagogies in EEE was recently published by Kappler (2016).

\subsection{Enterprise and Entrepreneurship Education at the University of Manchester (UK)}

The University of Manchester, following the trends of HEIs discussed earlier as well as explicitly requests by employers and the various professional bodies that accredit HE undergraduate and postgraduate programmes at the University, launched in 2000 the Manchester Enterprise Centre (MEC). Initially, MEC became the provider of EEE for science and engineering students. However, recognising the importance and benefits that such education can have on students from any discipline, since 2010, within Alliance Manchester Business School, MEC delivers EEE to students from any discipline of study. Nowadays, MEC is a recognised leader in EEE and an integral part of the University's commitment to provide enterprise and entrepreneurship learning opportunities to any student studying at the University. Through curricular and extra-curricular enterprise teaching, learning and business start-up support, MEC aims to develop graduates who can spot an opportunity, solve problems, innovate, manage risk and apply their subject knowledge in a commercial manner in order to transferring knowledge from the classrooms and laboratories to market opportunities whether as an entrepreneur or intrapreneur (MEC 2018; Phillips, 2010; Phillips, 2017). Further to that, MEC and the University of Manchester recognise that on leaving university and entering employment, graduates will face complex 'problems' of increasing interdisciplinary nature. Therefore, 
interdisciplinary education (IE) is key to MEC's activities. IE is here defined as combining of two or more academic disciplines into one activity to foster a learning environment that "analyzes, synthesizes and harmonizes links between disciplines into a coordinated and coherent whole" (Alvargonzález 2011, p. 388).

In the following sections, drawing from the literature and our own experience, we discuss lessons learnt from embedding EEE in the university curriculum. We focus on the design, delivery and assessment of two interdisciplinary enterprise undegraduate units.. We discuss our findings in the light of data collected from staff and teaching assistants' observations, students' reflective diaries and students' feedback. Finally, we draw some conclusions for the future development of interdisciplinary enterprise units with potential application to a much wider range of situations and academic areas of study.

\section{Description of two interdisciplinary enterprise units}

Exploring Enterprise (EE) and Interdisciplinary Sustainable Development (ISD) are two elective (optional) enterprise units offered to fisrt year and final year UG students studying any academic discipline at the University of Manchester, respectively. Units were designed following guidance for EEE discussed earlier but were adapted bearing in mind the level of study as well as institutional requirements and constraints. Common features to both units are:

Interdisciplinary. A typical student cohort tends to include students from the following disciplines: Civil Engineering, Mechanical Engineering, Physics, Biology, Chemistry, Maths with Finance, Computer Sciences, Environmental Sciences, Geography, Economics, Politics and Modern History and Business .

Experiential Learning based on PBL pedagogy. Students are presented with a 'problem' using a 'consultancyproject' brief. Students work in interdisciplinary teams and are expected to conduct research, meet outside of formal sessions to work on the project and manage their own time to submit project deliverables (coursework) to a tight dead-line. . This approach effectively gets students' minds focussed on a problem-solving attitude, ownership of the learning responsibility, in a move away from being spoon-fed with knowledge. Regular reflective practice is encouraged and captured in the form of an individual reflective diary at the end of the unit.

Delivery. Both units are delivered as weekly 2 hours sessions for 12 consecutive weeks. Interactive lectures, workshops and group activities are a key part of the weekly sessions. Both units include elements of learning 'about' enterprise and learning 'for' enterprise. Learning 'about' enterprise consists of introducing theoretical concepts with traditional lectures. Learning 'for' enterprise takes place with practical exercises through facilitated 
workshops, in class-activities and through working on projects. The ratio learning 'about'/'for' decreasing from the first year unit to the final year unit, in line with EEE QAA (2018) guidelines. .

Assessment. Typically consists of an individual or team consultancy-like reports, ateam presentation and individual reflective diaries as shown in Figure 1.

\begin{tabular}{|c|c|c|}
\hline & Y1: EE & Y3: ISD \\
\hline Lectures & $12 \mathrm{hrs}$ & $7 \mathrm{hrs}$ \\
\hline $\begin{array}{l}\text { Workshops A: } \\
\text { Application of theory }\end{array}$ & $6 \mathrm{hrs}$ & $7 \mathrm{hrs}$ \\
\hline $\begin{array}{l}\text { Workshops B: } \\
\text { Indiviual and team development }\end{array}$ & $6 \mathrm{hrs}$ & $11 \mathrm{hrs}$ \\
\hline Assessment & $\begin{array}{l}\text { - Individual report: } 60 \% \\
\text { - Team project: } 25 \% \\
\text {-Individual Reflective diary: } 15 \%\end{array}$ & $\begin{array}{l}\text { - Team project } 1: 20 \% * \\
\text { - Team project } 2: 40 \% * \\
\text { - Individual Reflective diary: } 40 \% \\
\text { *moderated by peer-assessment }\end{array}$ \\
\hline
\end{tabular}

Figure 1: Delivery and assessment comparison for EE and ISD unit

\subsection{Exploring Enterprise (EE) unit}

$\mathrm{EE}$ is delivered for first year undergraduate students, the aim of the unit is to provide a link from the students subject area to the commercial world with knowledge of enterprise and entrepreneurship and to develop skills useful in any work environment such as team working, research skills, time management and working with others from different disciplines. The cohort size ranges from 70-90 each year. Weekly sessions are delivered as one hour lecture followed by one hour workshop. The students prepare a report suggesting recommendations for a chosen 'real company' based on analysis of the business environment and market plus basic finance using tools and resources they have learned in class. This is assessed by individual report, team presentation and an individual reflective diary. Assessment weighing is shown if Figure 1. Further details about this unit have been published elsewhere (Phillips, 2008).

\subsection{Interdisciplinary Sustainable Development (ISD) unit}

ISD is delivered for final year undergraduate students. The aim of this unit is to develop students' knowledge, skills and competences neededto tackle global challenges and creating change towards sustainable development in a complex world. The cohort size ranges from 40-65 students. This unit adopts a blended learning approach. Theoretical concepts are primarily introdudec using a virtual learning environment. Weekly sessions are mainly dedicated to workshops. Through tackling two short team projects based on 'wicked' 
problems based on 'real world' scenarios, when possibledevised by 'real world clients', students gain understanding of the complex issues surrounding change towards sustainable development. The students prepare two consultancy-like reports for the 'real world client'. Two reports enable cumulative learning. 'Solutions' are expected to integrate and balance environmental, economic, social and ethical considerations. Assessment methods and weighing is shown in Figure 1. Further details about the origin and evolution of this unit have been published elsewhere (Tomkinson et al., 2008; Sanchez-Romaguera et al., 2016).

\section{Findings and discussion}

At this stage we were interested in reflecting on findings to inform our teaching. Findings are based on data collected from staff and teaching assistants' observations, students' reflective diaries and students' feedback. Student feedback was collected through various mechanisms: informal discussions in class, e-mails to the unit leader but mostly via standard institutional unit evaluation questionnaires which are made available to students at the end of the unit and provide an opportunity for students to provide anonymous feedback in a quantitative and qualitative manner (i.e. short comments).

\section{Findings from Exploring Enterprise (EE), first year unit}

Students on EE tended to have little experience of group work within a university context and no experience of writing a reflective journal, therefore this was a new experience to many. Some did not always see the relevance of the course beforehand and showed a lack of awareness of how their subject discipline fitted to the real world. Time management and organisation skills for many was poorly developed but there was evidence on completion that they were able to relate enterprise to their subject areas. Whilst face to face meetings between the students were also proven challenging, students used social media extensively to aid in sharing research with each other. It was found the journal acted as a mechanism to ensure all students contributed to the project and also encouraged attendance as it gave the students more material to reflect on. For students grades, it was found that the unit grade for EE was similar to the marks the students were achieving in their home schools, therefore despite differing assessment methods students did no better or worse in enterprise than their assessments elsewhere, showing that the best students are able to adapt to the differing requirements of different units. The students were comfortable working in interdisciplinary groups and this seemed to have no detrimental effect on the students experience.

\section{Findings from Interdisciplinary Sustainable Development (ISD), final year unit}

Prior to taking this unit most students have no interdisciplinary and no PBL experience. Interdisciplinary teamwork as well as working on 'real world' consultancy-like projects 
were found to be determinant factors for these students in choosing this unit. Ready to enter employment, students seemed keen to develop enterprising skills that employers are looking for. The format of the sessions was also positively received: very few traditional lectures, on-line resources and formative self-assessment to develop knowledge depending of specific needs (usually discipline ralted), and opportunity for challenging team discussions. In class time to reflect on the team performance in order to develop strategies for improvement was generallywell-received. The anonymous peer-review assessment, compulsory for all teams, was also highly regarded by students who felt there was a 'fair' mechanism to assess individual contributions to team projects.

However, for a few students the PBL experience was "too radical" and struggle with experiential learning, expecting some 'spoon-feeding'. This was the case particularly for specific disciplines. It is possible that such expectations were due to the university education students have received to date. One of the major challenges for some engineering and science students was being faced with 'no right answer' projects, possibly more used to assessment with a right answer (e.g. calculations). One could argue these challenges are 'discipline' related issues. The mix of disciplines in the group was generally a positive experience. Generally the more interdisciplinary the group the higher qulity deliverables. Although, in some cases, interdisciplinary was found to hinder the learning experience of some students who really struggle to work with students from other disciplines. The mix of discipline and differences in timetables did have an impact on students availability to physically meet outside the classroom as a team. However, students developed their own strategies, such as working in subteams and made very good used of technology to have 'virtual' team meetings. In terms of students performance, most teams find the projects challenging but engaging and tend to perform very well. In terms of the reflective diary, students had no prior experience. Over the years, as the unit evolved, guidance on refelctive practice was introduced. However, despite such efforts, the majority of students would like the reflective diary to be removed from the unit. Some see it as a waste of time especially when is due during a busy period for them, just before exam period. Generally, most students highly regarded the experiential interdisciplanry experience and feedback that should be a must in HE.

\section{Conclusions}

In this work we have shown that although most students while initially finding the interdisciplinary experiential learning challenging, generally found it a valuable experience.Based on our experience, we found that interdisciplinary teamwork doesn't seem to have much of an impact (positive or negative) on a first year unit as it does in a final year unit. To foster a more positive interdisciplinary learning experience, regardless of 
the level of study, we recommend to include activities at the beginning of the unit to emphasise and demonstrate what students from different disciplines might bring to the team in terms of skills and knowledge, and how that relates to a 'real world' working environment. Further to that, we also recommend to include more practical reflective practice guidance emphasising its value for self-development and life-long learning.

\section{References}

Alvargonzález, D (2011) Multidisciplinarity, interdisciplinarity, transdisciplinarity, and the sciences, International Studies in the Philosophy of Science, 25, pp. 387-403

Gibb, A.A. (2005),Towards the entrepreneurial university entrepreneurship education as a lever for change, Policy Paper No. 003, National Council for Graduate Entrepreneurship (NCGE), Birmingham.

Jones, B., Iredale, N. (2014) Enterprise and entrepreneurship education: towards a comparative analysis, Journal of Enterprising Communities: People and Places in the Global Economy, 8 (1), pp.34-50.

Jones, P.J., Forbes-Simpson, K., Maas, G., Newbery, R. (2015) Beta: An experiment in funded graduate start-up, Industry and Higher Education, 29 (5) , pp. 405-418

Klapper, R. G., Farber, V. A. (2016) In Alain Gibb's footsteps: Evaluating alternative approaches to sustainable enterprise education (SEE), The International Journal of Management Education, 14 (3), pp.422-439

Kolb, D. A. (1984) Experiential learning: Experience as the source of learning and development, Englewood Cliffs, NJ, Prentice Hall.

MEC, Manchester Enterprise Centre website (2018). https://mec.portals.mbs.ac.uk/

Phillips, R.A. (2008) The Use of Personal Journals for Assessment of an Undergraduate Enterprise Module Journal of Asia Entrepreneurship and Sustainability 4 (4), pp.7789.

Phillips, R.A. (2010) Encouraging a more enterprising researcher - the implementation of an integrated training program of enterprise for Ph.D. and postdoctoral researchers Research in Post Compulsory Education, 15 (3), pp. 289-299.

Phillips, R.A. (2017) Measuring Entrepreneurial outcomes from a residential enterprise school for postgraduate researchers Journal of Asia Entrepreneurship and Sustainability, 13 (2), pp. 62-89.

QAA, Quality Assurance Agency for Higher Education (2018) Enterprise and entrepreneurship education guidance for UK higher education providers, available online at: $\quad$ http://www.qaa.ac.uk/en/Publications/Documents/Enterprise-andentrpreneurship-education-2018.pdf

Tomkinson, B., Tomkinson, R., Dobson, H., Engel, C. (2008) Education for sustainable development - an inter-disciplinary pilot module for undergraduate engineers and scientists, International Journal of Sustainable Engineering, 1(1), pp. 69-76. 
Sanchez-Romaguera, V., Dobson, H. A., Tomkinson, C. B. (2016) Educating engineers for the Circular Economy, Proceedings to the 8th International Conference on Engineering Education for Sustainable Development, Bruges, Belgium. September 4-7, pp. 9-19.

Volkman, C., Wilson, K.E., Rabuzzi, D., Vyakarnam, S., Sepulveda , A. (2009) Educating the next wave of entrepreneurs: Unlocking entrepreneurial capabilities to meet the global challenges of the 21 st century. A report of the Global Education Initiative, available on-line at: http://www.weforum.org/pdf/GEI/2009/Entrepreneurship_Education_Report.pdf 